
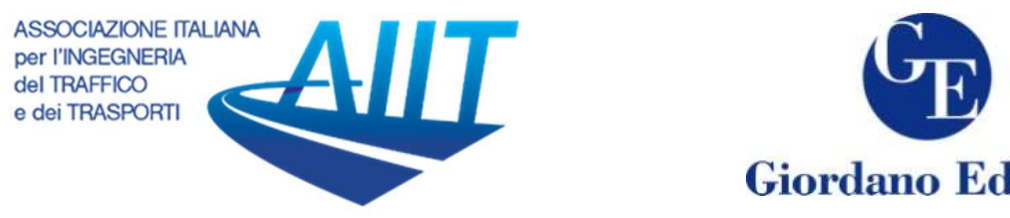

Giordano Editore

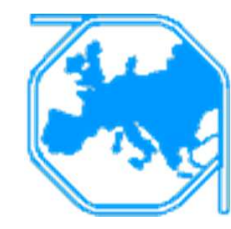

\title{
An Economic and Social Evaluation Approach to the Sustainable Redesign of Old Urban Street Infrastructure
}

\author{
Elisabetta Venezia ${ }^{1 *}$, Lidia Zakowska ${ }^{2}$ \\ ${ }^{1}$ Department of Economics and Finance, University of Bari Aldo Moro, Bari, Italy, 70124 \\ elisabetta.venezia@uniba.it \\ 2 Department of Civil Engineering, Politechnika Krakowska, Warszawska 24, 31-155 Krakow, Poland \\ Email: lzakowsk@pk.edu.pl
}

\begin{abstract}
The aim of this study is to introduce an economic evaluation approach into the process of redesigning old urban street infrastructures. Several variants of street cross-sections are proposed for redesigning, both in Krakow, Poland and in Bari, Italy, and the optimal sustainable design options are suggested. An experimental economic method is then applied to evaluate the proposed sustainable options. Social return on investment (SROI), as a form of evaluation that contributes to a wider analysis of public investments and uses monetary values to represent the social and economic results. It provides information on creating economic and environmentally sustainable values.

Economic evaluation results suggest how society perceives the implementation of sustainable transport investments by assuming the most important aims to be addressed in an urban context, such as sustainability, accessibility and affordability. The innovative evaluation approach enforces the decisionmaking process and helps to properly allocate economic resources.
\end{abstract}

Keywords: urban street, redesigning, sustainability, economic evaluation

\section{Introduction}

The traditional approach to the economic evaluation of engineering investments in Poland, especially in the transport sector, remains counting all the spending needed for design, construction and making the planned section or space operative. Knowledge and research in the transport economy is constantly developing and moving towards inclusion of multiple social values which support sustainability. This trend of including wider social values and returns into the economic evaluation of urban investment is especially valid for historical old cities, which are usually densely populated with old streets which need to be redesign and reconstructed to serve sustainable and environmentally friendly mobility (Campisi et al. 2019). While the majority of investments are connected with redesigning of car-traffic streets into more walking and cycling streets and are financed

\footnotetext{
* Corresponding author: Elisabetta Venezia (elisabetta.venezia@uniba.it)
} 
by the cities, knowledge-based calculations must support decision makers on how to spend public money in order to be accepted by social opinion and such calculations cannot ignore a wide scope of environmental and social aspects.

Krakow city is one of such historical city, where air pollution is one of the most serious problems, and where a third of the total pollution comes from road transport. Thus, any investment in redesigning traffic corridors that are usually dominated by or exclusively used by cars are now being changed into historical streets dedicated to cleaner forms of transport and new pedestrian and bike routes.

The second case study is the Italian city of Bari, which is also an old European city in which private cars are the dominant form of transport; like Krakow, Bari is also looking for more sustainable solutions for mobility through proper infrastructural changes.

This paper is novel in that it presents an innovative methodology for evaluating investment projects that renew the urban context from a social and environmental point of view. The chosen methodology is the SROI (social return on investment). SROI is a powerful method for measuring possible non-financial values of investment projects. It contributes to a wider analysis of investments and offers an overview of how the generated effects of such investments have been appreciated and experienced by beneficiaries and stakeholders. The two presented cases help the reader to reach the objective of appreciating the sustainable aspects related to the redesigning of historical urban streets by considering further elements which are the expression of social relevance.

The paper is organised as follows. In Section 2, current evaluation procedures related to the transport sector are presented. Section 3 illustrates the case study of the Italian city of Bari. Planning indications are provided with specific regard to current transport infrastructures and the transport supply, the city is then contextualised. In Section 4, we use the same structure to present the Polish case study of Krakow, and a specific focus is given to two interventions to be implemented in the old city. Section 5 contains the SROI evaluation procedure applied to the interventions and the obtained results are discussed. In the final Section 6, we present our conclusions.

\section{Evaluation procedure in the transport sector}

Economic feasibility procedures still generates discussion between researchers, investors and suppliers, leading to the need for more accurate and case-specific costbenefit analyses or for alternative methods (Melo et al. 2020). Economic assessment is also characterised by the continuous evolution of methodologies, with consideration to political trends and global strategies. Recent developments are aimed at enlarging the scope of socio-economic evaluation and at paying more appropriate consideration towards indirect economic elements, such as externalities. However, in practice, public and private parties often fail to resolve the problem of externalities on their own, mainly because externalities are difficult to measure. Therefore, social, environmental and community impacts frequently do not convert into numbers and reliable quantitative measurements. These aspects have featured in the most recent debate an international brainstorming among which there are ways of including wider economic impacts to project assessment (Chèze and Nègre, 2017).

The project investment appraisal provides indications of the project's final impact on the economic system and social acceptability through a comparison of the evaluated effects and the predetermined criteria of acceptability (Pearce, 1998). In this regard, the characteristics of SROI are highly attractive because they overcome some of the limitations of the cost-benefit analysis (Venezia and Pizzutilo 2018, Venezia and 
Pizzutilo 2020). In accordance with Lombardo et al. (2019), SROI represents one of the most established social impact assessment methods, being an indicator that satisfies the main essential requirements of social impact evaluations, namely:

- the ability to measure outcomes rather than tracking output;

- the ability to compare the value of different types of benefits;

- the consideration of counterfactual evidence in impact creation;

- the ability to provide guidance towards effective and coherent funding decisions.

Therefore, the rationale behind the SROI is that each investment should consider not only the financial value it produces but should also include a wider range of benefits. Such benefits are not considered by the main indicators employed in financial analysis, which account only for the financial value. One of the most popular indicators is the return on investment (ROI), which compares the gain or loss generated on an investment relative to the amount of money invested. Nevertheless, most of the activities linked to public usage generate impacts that include other social, economic and environmental dimensions (Lombardo et al., 2019) which are not considered in the traditional indicator of economic appraisal. This is the reason why there is a need to consider more accurate indicators, such as SROI, because they provide not only numerical estimations of the social impact but also help organisations to understand the social value created by an activity. These aspects enable them to make better informed decisions, to better connect with stakeholders in order to meet their expectations, and to change management strategies according to well-defined goals. Meira et al. (2020), for example, used this indicator to evaluate sustainable urban transport policy by using the Origin-Destination Survey of the Metropolitan Region of Recife (Brazil) to estimate social effective speeds. Furthermore, Muvawala et al. (2020) estimated the socio-economic impacts of transport infrastructure investment in Uganda.

In this paper, we aim to provide a measurement of some of the environmental and social impacts, and we focus on the quantitative and qualitative evaluation of the positive (benefits) and negative (social costs) elements that characterised two European areas, the metropolitan area of Bari in Italy and Krakow in Poland, which are trying to improve urban traffic conditions by promoting bicycle and pedestrian mobility. We show how these two components of urban mobility often clash with the territorial accessibility or practicability of urban crossings. Also some other physical barriers are relevant in urban contexts.

\section{The metropolitan city plan of Bari}

In the following sections, the case study of the metropolitan city of Bari is presented. Firstly, the transport sector's peculiarities are presented with regard to the bicycle plan and the territorial area is then contextualised.

\subsection{Transport issues}

In all the transport systems present on the territory, some dysfunctions have been detected. The main examples are:

- inadequate hierarchy of networks (road transport; especially in the Bari hub);

- insufficient capacity for numerous sections of the networks (road and rail transport);

- shortage and/or obsolescence of vehicle fleet (public transport);

- lack of quantity and/or qualification of personnel (public transport);

- managerial inefficiencies (land, sea, and air public transport);

- low quality of the service offered (land, sea and air public transport); 
- lack of integration between the different systems of transport (land, sea and air public transport, including the transportation of goods);

- strong imbalances in the distribution of demand in the territory etc.

The most critical issues are concentrated in Bari, where the demand is higher and the effects of the deficiencies are greater; the high mobility difficulties in this area, however, while directly affecting urban transport, have a negative impact on the suburban transport of the entire metropolitan city.

The poor functioning of public transport in this area, in fact, makes movements in the main transport nodes difficult for all users directed towards it (around 47\% of total metropolitan movements). Therefore public transport service users are led to choose private car transport in the hope of reaching the final destination more easily, aggravating the strong modal imbalance that already exists today (only $20 \%$ of total metropolitan journeys are made by public transport).

The general lack of public transport, moreover, combined with the shortcomings of the road network and those of the main intermodal nodes (port, airport and interport), make the functions connected to the role of Bari as a terminal of the Adriatic Corridor extremely difficult.

The Metropolitan Biciplan has as its strategic objective the promotion of sustainable urban mobility throughout the metropolitan area in line with the regional planning instruments OP (operative programme) of Puglia 2014-2020 as well as national and European planning, which attach particular importance to interventions that aim to increase sustainable mobility in urban and suburban areas (Città Metropolitana di Bari, 2015; https://por.regione.puglia.it/en/homepage). The advantages are:

- the incentive to use the bicycle not only for leisure time but also for movements that are functional to the activities of daily life of citizens, with a consequential reduction in the use of private and public motorised vehicles, which are the main producers of $\mathrm{CO}_{2}$ and $\mathrm{PM}_{10}$;

- an opportunity for the territory for the realisation of an efficient integrated sustainable mobility system that can encourage national and international cycling tourism;

- the integration of cycling mobility with other public transport systems and connections with the main logistics hubs of the metropolitan area (airport, railway stations and exchange car parks) with consequential disincentivising of private vehicle use;

- an opportunity to optimise the entire road layout of the municipalities through inserting cycle paths in connection with a system of the various urban agglomerations of the territory in accordance with a model that systemises and satisfies the needs of all users, widely improving the road safety and quality of life.

The planned interventions are aimed at favouring the modal conversion of urban and suburban movements towards low environmental impact or zero-emission modes of transport with, a particular emphasis on pedestrian and bicycle mobility in short-medium to long-range travel, especially in low-lying areas that in Apulia represent a significant percentage of the entire regional surface, to bike-sharing, car sharing, and public collective transport with electric or hybrid vehicles.

The pursuit of the above objectives requires a synergic action implemented on multiple fronts. The improvement in the offer of cycling mobility cannot but proceed hand in hand with the improvement in demand. Therefore, it is not enough to set up an adequate network infrastructural; it requires a careful awareness-raising activity in the population which contributes to spreading the perception of the use of the bicycle not only as a sport 
but also as a lifestyle with a view to developing fully in line with the policies promoted on the subject at community level, through specific communication campaigns. This also implies the implementation of a set of interventions aimed at improving the safety perceived by the cyclist in the use of the vehicle and the provision of a series of facilities for cycling.

This is the vision placed at the base of documents, such as:

- the Brussels Charter, signed by the European Parliament on May 15th 2009 during the final day of the XV International Conference on cycling Velo - City, with which the signatory cities have committed themselves to reaching at least $15 \%$ of journeys by $\begin{array}{lllll}\text { bicycles in their } & 2020\end{array}$ (https://ecf.com/sites/ecf.com/files/Charter_of_Brussels.pdf);

- the ZeroVision program, launched in 1997 by the Swedish Parliament which radically changes the approach to the problem of road safety, starting from the idea that nobody should be killed, seriously injured or harmed due to a car accident and that human and social costs that derive from it can no longer be accepted as an inevitable effect (https://www.cga.ct.gov/2007/rpt/2007-R-0635.htm).

These concepts are fully applied in the policies promoted in the Apulian region, as defined in the Regional Transport Plan (PRT) and in the Regional Territorial Landscape Plan (PPTR) and in the Metropolitan Strategic Plan (www.regione.puglia.it).

The present plan is based on a basic strategy: to build a response to the demand for both tourist and recreational cycling mobility, taking advantage of all the opportunities that this entails in terms of local marketing, and those citizens of the metropolitan area of Bari, who will also be able to use the bicycle instead of the car for their daily journeys, thus achieving remarkable results in terms of reducing pollution and raising quality of life (Città Metropolitana di Bari 2015).

\subsection{State of art, context analysis and legislative framework}

The metropolitan city of Bari was born with the aim of favouring the development of its own territory in a harmonious way, overcoming the physical limits of the municipal administrations. Through the coordination action of the new body defined by the Delrio law, administrations have the opportunity to express their opinions, their needs and formulate their requests. By doing so, municipalities which take part in the metropolitan city of Bari trust each other and share solutions that can constitute an opportunity for the entire territorial socio-economic system of reference (Città Metropolitana di Bari, 2015).

Figure 1 presents the geographical location of the area to which we are referring.

Law no. 56 of the 7th April 2014, Article 1 Paragraph 2, defines metropolitan cities as a vast territory with the following purposes: care of the strategic development of the metropolitan territory; promotion and integrated management of services, infrastructures and communication networks of interest to the metropolitan city; care of institutional relations at their own level including those with cities and European metropolitan areas (https://www.gazzettaufficiale.it/eli/id/2014/4/7/14G00069/sg). 


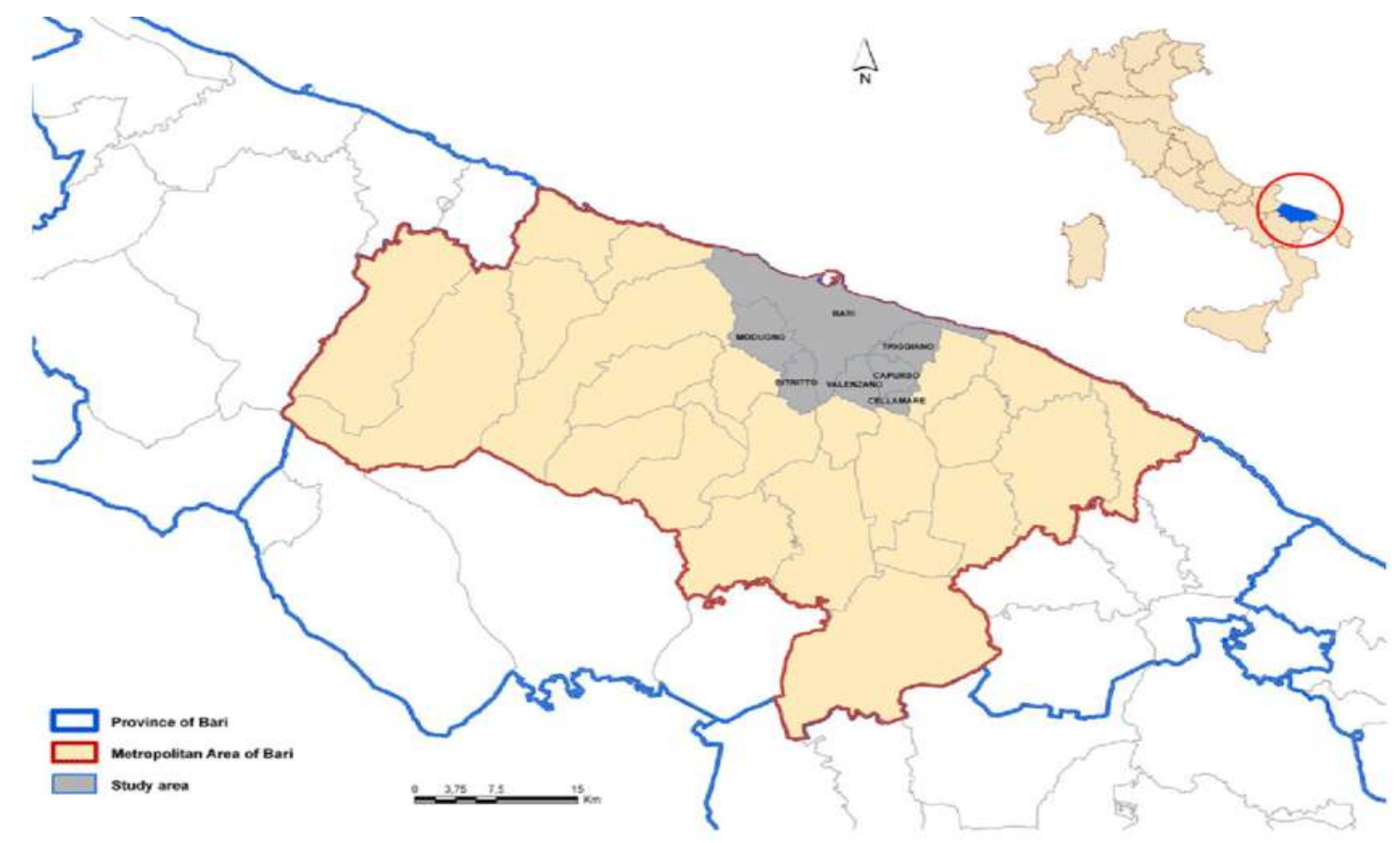

Figure 1 - Metropolitan Area of Bari

Source: Researchgate.com

The statute and the governance model of the strategic planning process of the metropolitan city of Bari, approved by resolution of the Metropolitan Council no.1 / 2016, operates effectively, in a constant and continuous action of co-planning with the fortyone metropolitan municipalities. This allows them to implement their development programs using the programming tools of the Apulia region, national government institutions and the European community and, at the same time, to contribute to the growth and development of the entire metropolitan territory (https://www.federalismi.it/nv14/articolo-documento.cfm?Artid=32540).

In this context, the metropolitan Biciplan (Bike plan) is included, a planning tool that is drawn up by the metropolitan city, which can be considered as an example of that process of planning and co-planning described above.

Taking into account the contents reported in the art. 22 of Law no. 340/2000, establishing the Urban Plans of Mobility (PUM), the Biciplan illustrated here is aimed at "satisfying mobility needs of the population, ensuring the reduction of atmospheric and noise pollution levels, the reduction of energy consumption, the increase in safety levels of the transport and road traffic, minimising the individual use of the private car, traffic moderation, an increase in transport capacity, an increase in the traffic percentage of citizens transported by public systems, an increase in carpooling and car sharing solutions and the reduction of congestion in urban areas" (https://www.parlamento.it/parlam/leggi/003401.htm).

The Biciplan is, therefore, consistent with the statute of the CMB (Città Metropolitana di Bari - Metropolitan City of Bari), as a plan that is proposed as a tool able to "summarise" and define strategies and objectives for the establishment of an interconnected network of interventions that involves the entire metropolitan area, providing for urban routes as well as connection routes between urban areas. In some cases, these bike routes were already present in the road networks, while in other cases they are part of future infrastructure realisation or expansion. 
Therefore, this plan provides strategic and programmatic guidelines in the urban area, thus entrusting the implementation of individuals' interventions and consequential and subsequent fulfillments of technical and administrative design to the competence of the individual administrations concerned, by direct management or signing of specific agreements.

The metropolitan city of Bari has an area of $3,862.88 \mathrm{~km}^{2}$, resulting the third area in terms of extension in Apulia, after the Provinces of Foggia and Taranto. It is characterised by a territory that is $80 \%$ hilly ( $<700$ meters of altitude) and $20 \%$ flat ( $<300$ meters).

To be able to make a description of the current settlement system of the territory of the metropolitan city of Bari, it is necessary to reconstruct the evolutionary dynamics that since the $1950 \mathrm{~s}$, it has profoundly changed. It is worth remembering at least some macroscopic data, which enable assessment of the relevance of the transformations of the settlement system during this period. The urban phenomenon, which in the early 1950s covered an area of approx. 4600 ha, reached a fivefold increase over a period of fifty-five years.

In short, it is possible to state that in addition to the primarily role of the capital, it is possible to identify centres and systems of centres (the territorial cornerstones) characterised by a different consistency of supra-local services. There are some that can deliver more relevant services of public interest and less frequent services for businesses, which constitute polarities of reference for the inter-urban and trans-metropolitan territories. There are also municipalities that are near to these polarities, they have a lower endowment, but still able to guarantee a varied offer, especially if they are close and can be considered as a system. While for some municipalities mainly prevail specialised offers, in different fields; however, the majority of the municipalities in the first and second bands around Bari appear almost completely devoid of the offer of services, except for some small amenities. Furthermore, the Murgian area represents a weak reality in terms of territorial endowments, but particularly relevant if seen as 'urban garrisons' in the landscape of Alta Murgia. Seen in this perspective, they can perform roles similar to those of the cities of south-eastern Murgia in the field of the fruition of landscape assets.

\section{The Metropolitan City of Krakow}

\subsection{Transport issues}

Krakow is the former capital of Poland, dating back to 1257 as a town on the Magdeburg Rights, and today it is the second largest city in the country in terms of the number of inhabitants and the space occupied. It is situated in an area of $327 \mathrm{~km}^{2}$ in southern Poland. The number of permanent residents is 760,000 , but more than 150,000 students and another 200,000 workers make the total number moving within Krakow every day around 1,000,000. Students constitute a very creative and mobile part of the community. The density of the population is not evenly distributed within the city area. There are regions in the city where density rate is relatively high $(11,900$ persons per square kilometer) and others where it is relatively low ( 710 persons per square kilometer). Car ownership rate is over 500 cars/1,000 inhabitants and shows a tendency to grow further. However, the modal split in Krakow is very good: $43 \%$ of the total number of trips are made by public transport, only $27 \%$ by private transport, nearly $29 \%$ by pedestrian movement and only about $1 \%$ of trips are made by bicycle.

The Krakow metropolitan area is app. $4,000 \mathrm{~km}^{2}$, with a population of 1.4 million. The mobility rate amounts to 2:1 trips per person per day. Each day, over one million 
passengers in Krakow use public collective transport (buses and trams), which consists of 26 tramlines and 151 bus lines (including 65 regional lines). There are also twelve bus lines and two tramlines operating at night. The bus system operates on a road network of over $500 \mathrm{~km}$ and a tram network of over $90 \mathrm{~km}$. The number of vehicles in operation every day includes 216 trams and 458 buses. The existing public transport system is planned to be complemented with rapid rail transit in the future. Two options are being considered: urban rail (SKA) operating on the existing urban network or, and subject to finance, an independent metro system. The main principle of the spatial policy adapted in the new planning scheme for Krakow and approved by the Council in July 2014, is to concentrate future development or redevelopment on the existing urban areas without extending the city's boundaries (see Figure 2). The Krakow planning system, governed by the national planning regulations, is based on two levels of planning documents: the general planning scheme for the entire municipality and local plans covering parts of the city (districts, neighbourhoods, and other urban complexes). The planning objectives respond to the main strategic development goals set out for the metropolitan area. These are:

- development and improvement of the main metropolitan functions, as e-industries, science and research, culture, mobility;

- improvement of the quality of public space;

- protection of cultural heritage and environmental values;

- development of sustainable transport and technical infrastructure.

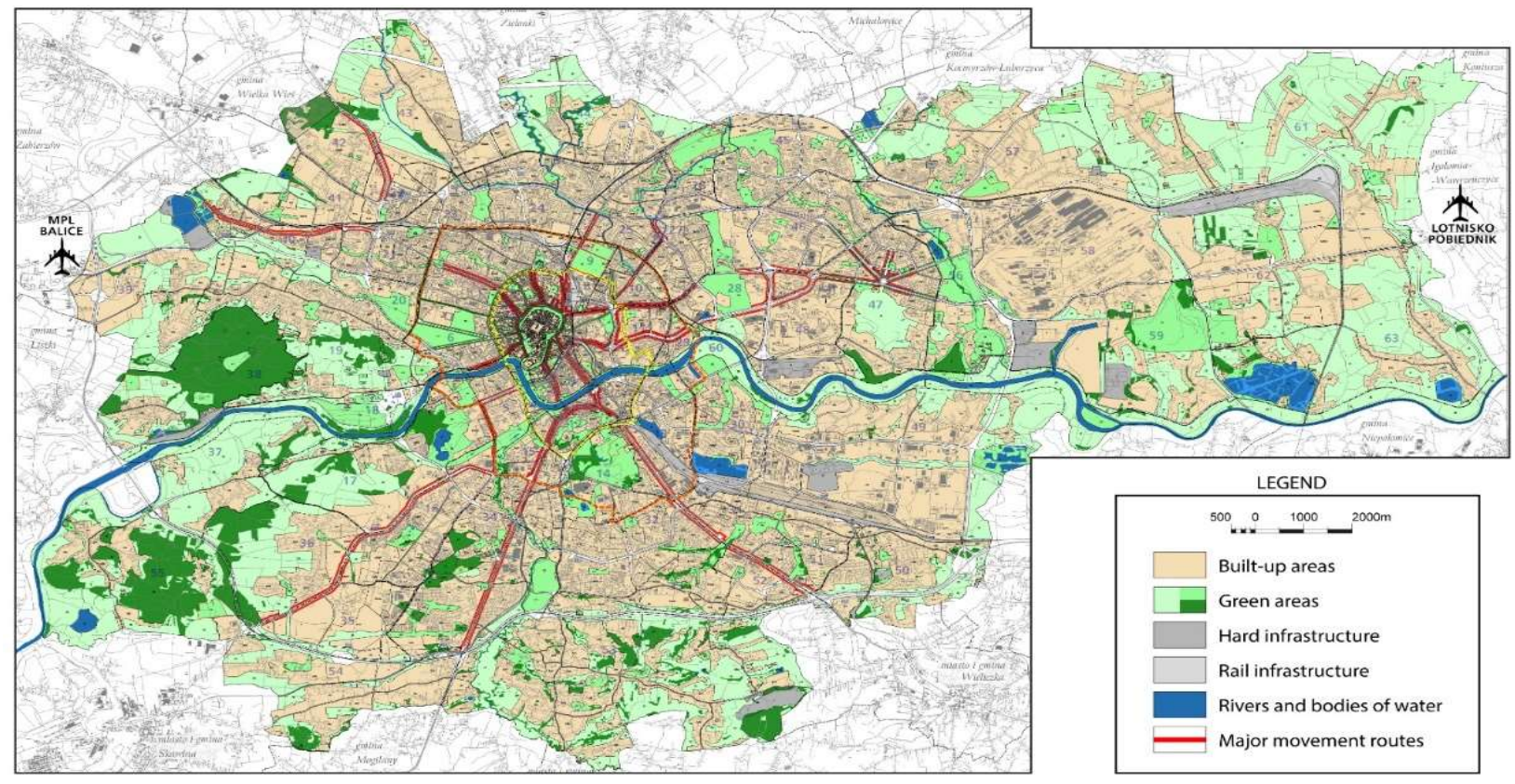

Figure 2 - Urban and transport spatial structure of Krakow

Source: Krakow City Office (2014) Study of conditions and directions of spatial development for Krakow. Uchwala Nr CXII/1700/14, July 2014.

\subsection{State of art, context analysis and legislative framework}

A number of planning policy documents at the national government level indicate the need for the integrated planning of spatial structure and transportation systems in cities. The "National Transportation Policy for 2006-2025" (Polityka Transportowa, Warszawa 2005) and a government document entitled "National City Policy" (Krajowa Polityka 
Miejska, 2014), as well as the Polish Ministry for Infrastructure and Development (Ministerstwo Infrastruktury i Rozwoju) strongly recommend a balanced consideration of the functional, spatial, economic and social aspects in the planning and development of cities. Both documents specifically point out the necessity of not only planning new residential areas where residents can meet their daily needs within convenient mobility modes, but also of redesigning existing infrastructure in a more sustainable way. They recognise the impact of spatial and functional structure on the level of generated individual car traffic and its potential reduction. The regulatory main document in Poland describing urban planning and development is the Planning and Spatial Development Law (Ustawa, 2003). The document defines the goals and scope for planning and development policies and allocates respective responsibilities to local governments and administration. The underlying principles are spatial harmony and sustainable development. The law states that development of space should ensure the creation of a harmonious whole and enhance the ordered relations of all relevant aspects and conditions: functional, socioeconomic, environmental, cultural and aesthetic. These requirements are placed on two planning documents in particular describing the functional and spatial structure of cities: Conditions and Directions of Development Study (Studium, Krakow 2014) and local development plan. At the municipal level, the problems of integrated spatial and planning of Polish cities are further considered in documents such as Transport Policy (Polityka Transportowa, Warszawa 2005) and Development Strategy (Strategia, Warszawa 2012). Both documents determine the possible impact of land use on transport systems but are usually limited to general recommendations. Only few a Polish cities have adapted transport policy documents, with Krakow being the first one in 1993. Krakow's Transport Policy goal is compatible with the document entitled "Operational Objective II - 2 Improvement of Transport Accessibility" (original title "Cel operacyjny II - 2 Poprawa dostępnosci komunikacyjnej") and with "Integrated Plan of Public Transport Development in Krakow" (Zintegrowany Plan, 2008). In cities in which Transport Policy documents have not been adapted, the relevant elements of the policy are incorporated in their general planning schemes. However, in most of these documents, recommendations regarding the integration of spatial planning and transport are of a general nature and do not indicate how exactly the postulates should be implemented.

In Poland from 1997, the idea of sustainable development has been included in the constitution, but only after joining the EU in 2004 has it been widely researched and respected. Today, innovative planning has been recognised as sustainable planning which promotes clean mobility, is energy saving and enhances quality of life and promotes good health (see Figure 3). It overlaps with other policy areas, for instance, sustainable cities are more walkable, greener cities that respect sustainable mobility principles, which benefit everyone. Many projects and initiatives are run in Krakow city which lead to the transformation of the urban and transport space, from a space in which the car dominates to a more sustainable space. Two examples of such transformations in Krakow deal with a pedestrian street (the redesigning of an old historical street in the Old Town to a more walkable and beautiful passage) and bike routes (redesigning space around high-traffic streets to construct separate cycle and foot lanes connecting the city centre with new bridges for clean mobility) promoting cycling and walking as sustainable mobility. 

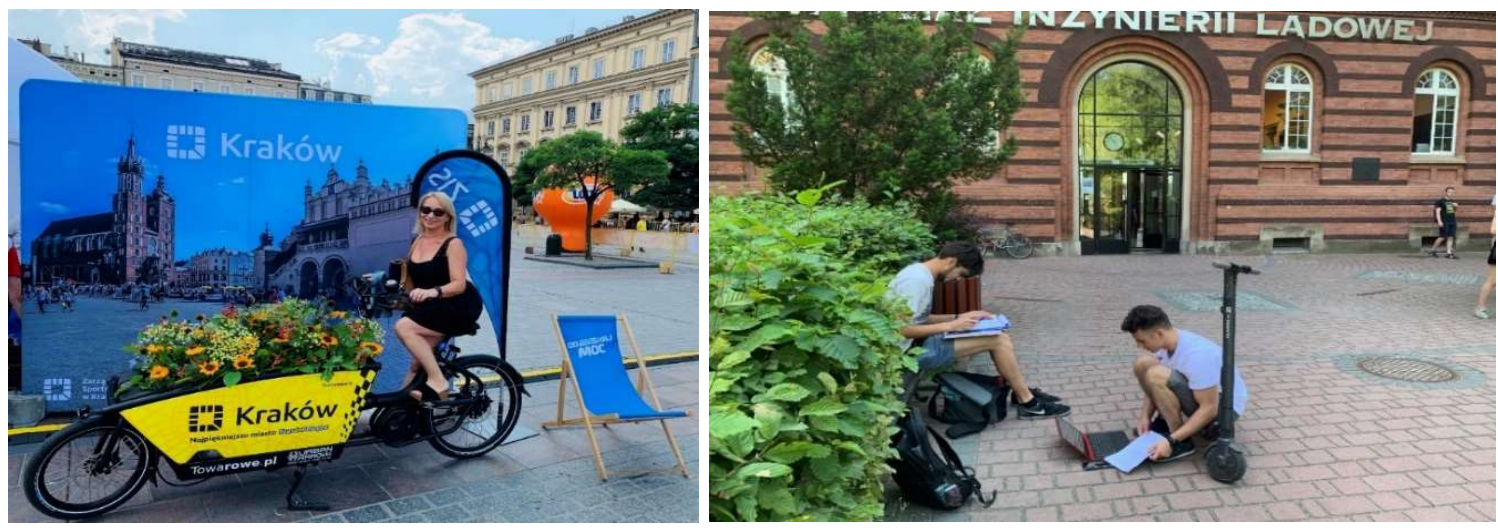

Figure 3 - Examples of the initiative promoting clean mobility at the Market Square in Krakow (left) and a new personal mobility device and the mobility behaviour of students in Krakow

Source: Photos by the authors

\subsection{The case of Krakow city}

Two sections in Krakow were chosen by the authors for recalculation of spending on current sustainable rebuilding projects, where the only costs evaluated by the city investors were connected to technical aspects, like engineering design, construction, and supervision. Both cases were selected and elaborated, based on the actual characteristics of the Krakow city urban and transport situation, especially with regard to cycling (Figure 4).

Data from the latest measurement of bicycle traffic in Krakow, from June 2019, show an increase in bicycle use compared to the same period in 2018, which means that inhabitants more often choose a bike as a means of moving around the city.

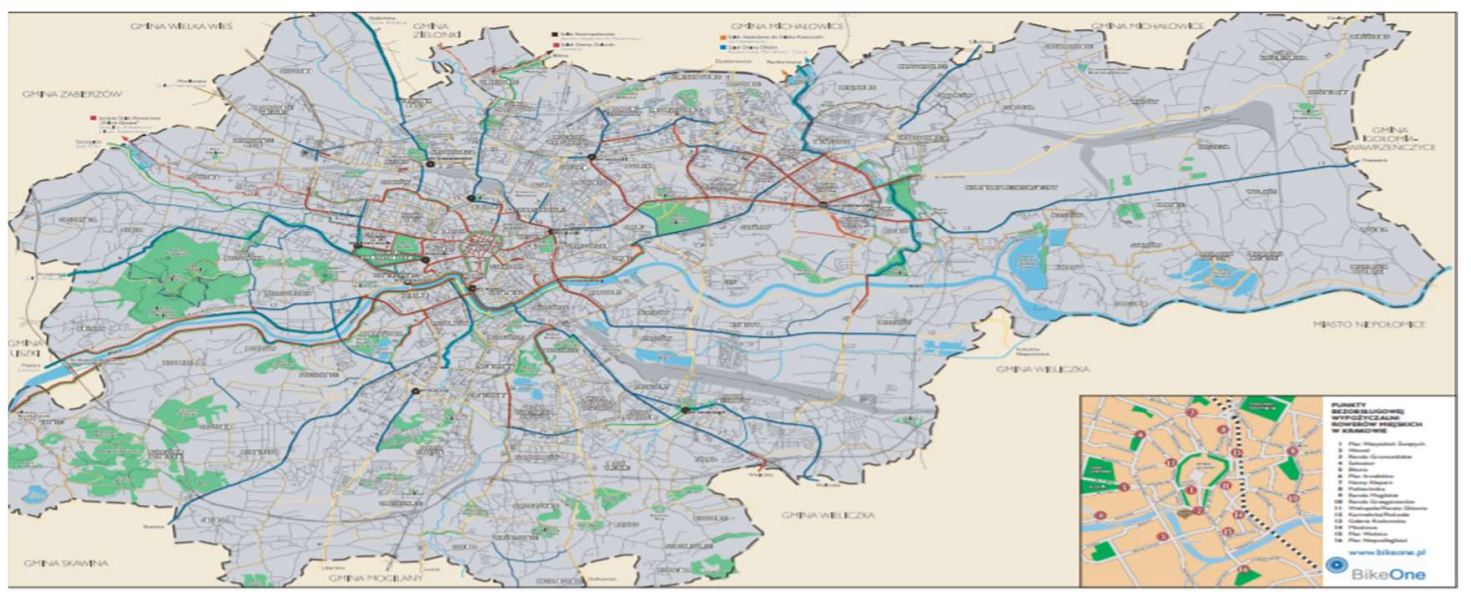

Figure 4 - Krakow bicycle infrastructure

Source: http://www.krakow.pl

The bicycle infrastructure of Krakow is well developed. There are also new cycling routes being built and planned. Krakow was the first city in Poland that opened the old town for cyclists, also in Krakow, the first contra-lane for bikes was made. Officials have announced the construction of more than $60 \mathrm{~km}$ of bicycle lanes in the city. For new cycle routes last year, the city authorities were planning to spend 68 million zlotys. Each month, the number of cycling paths in the city increases. There are actually $221 \mathrm{~km}$ of cycling 
infrastructure in Krakow, including $140 \mathrm{~km}$ of bicycle and cycling routes, $16 \mathrm{~km}$ of contra-lanes and bicycle paths. Currently, two big investments in the area of cycling infrastructure are being realised in the city: bicycle path from Przybyszewskiego street along the streets: Armia Krajowa and Jasnogorska to the border of the city of Krakow, and the construction of a cycle path from the bridge on the Vistula river connecting Kazimierz with Ludwinow, along Konopnickiej street to the Matecznego roundabout, then along Kamienskiego with a footbridge.

\section{Case 1 - Biking route}

This case covers the design and construction of the road for bicycles from the bridge on the Vistula river connecting the Kazimierz district with the Ludwinow area along M. Konopnicka Street to the Matecznego roundabout, along Kamienskiego Street with a footbridge on Kamienskiego (see Figure 5).

The whole project is located in the district XIII Podgorze, Krakow, and assumes the execution and designation of a total of approx. $5.25 \mathrm{~km}$ of bicycle lanes. The main objective of the project is to contribute to the changes in urban mobility leading to the reduction of environmentally disruptive pollutants to the inhabitants of the agglomerations and to the increased energy efficiency of the transport system through the expansion of paths and bicycle infrastructure.

The overall objectives of the project include:

- $\quad$ increasing the available cycle paths;

- increasing the comfort of travel and improving the safety of users;

- reducing the negative environmental impacts of road transport;

- enriching and enhancing the tourist offer of the city by creating an infrastructure to enable active tourism.
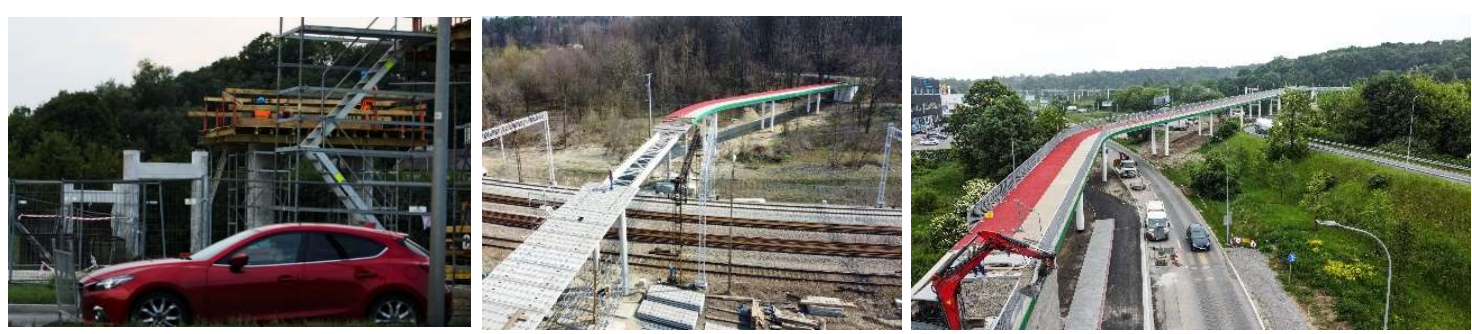

Figure 5: Construction of the cycle bridge segments over Kamienskiego Street in Krakow

Source: Photos by the authors (left) and from https://zdmk.krakow.pl/albumy/budowa-kladki-wzdluzkamienskiego/ (right)

Total spent: $€ 4,864,705.00$, in which grant covered: $€ 4,058,430.14$, where:

$€ 2,336,448.6$ - cycle/foot bridge (500 m long),

$€ 194,096.26$ - design and documentation,

$€ 2,336,448,6$ - construction costs (labour and materials).

\section{Case 2 - Old Town pedestrian street}

This case covers total renovation, reconstruction and rebuilding of an old historical street in Krakow, Slawkowska Street, running from the Main Square to the Planty (see Figure 6). The total length of the street is $400 \mathrm{~m}$.

Total spent: $€ 2,933,243.97 €$, where selected investments and works were: $€ 260,779.44$ - ZIKIT (Municipal Infrastructure and Transport Management) 
(lighting, telecommunication and traffic organisation), $€ 886,964.02$ - MPEC (municipal company of the energy industry)

(pavement),

$€ 675,757.24$ - MPEC (central heating),

$€ 886,964.02$ - new pavement works,

$€ 224,158.88$ - hydraulic works.
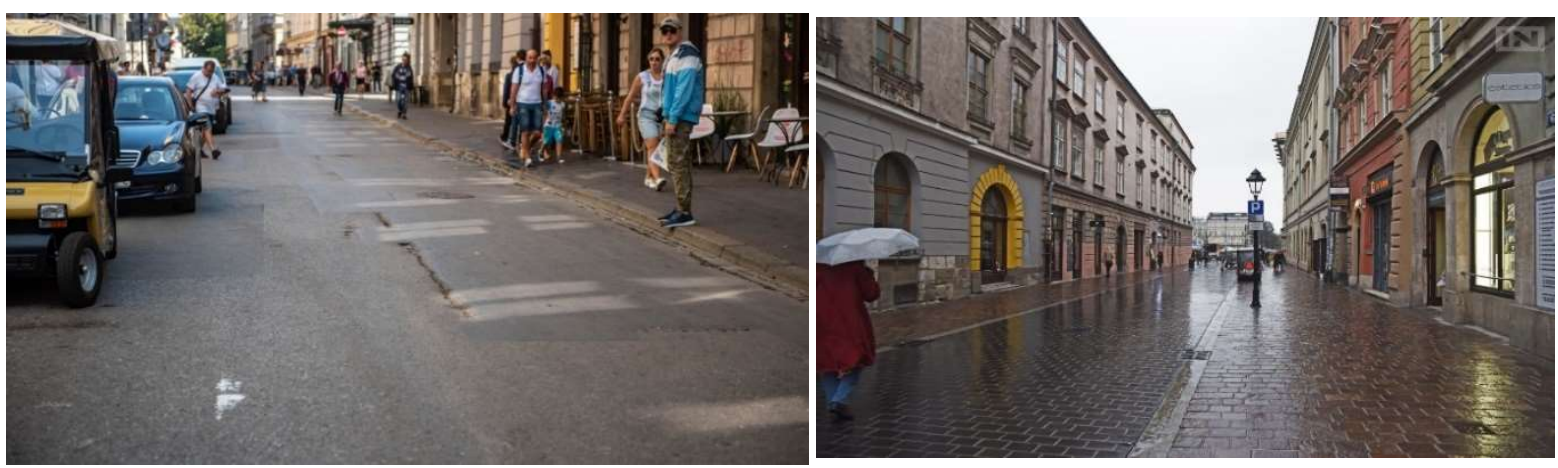

Figure 6 - Slawkowska Street in Krakow before (left) and after (right) the reconstruction in 2019

Source: Photos by the authors

\section{Results}

The economic evaluation shows the economic feasibility and the social relevance of the interventions mentioned in Section 4.

The development of the calculation for the planned intervention in the Bari area is described in detail below. A summary of the results for both this case study and the Krakow case study follows.

The benefits deriving from the intervention in the city of Bari are divided into direct, indirect and social economic (quantitative and qualitative).

The direct benefits are zero as the infrastructure will be used completely free of charge, so no fee is payable and no ticket will be required to travel along it.

The indirect benefits relate to the tourism related to the use of the cycle path by cycle tourists, and the expenses incurred by any cycle excursionists and residents.

Initially, tourist movements in Apulia were detected, obtained from the Puglia Promotion Observatory in 2018 (https://www.agenziapugliapromozione.it/portal/). Tourist arrivals in 2018 amounted to almost four million, while tourist who stay overnight (called presences) amounted to around 15.1 million. The estimated number of potential cycle-tourists was calculated taking into account that, of all holidays, the percentage of cycling holidays is around $2 \%$, which equates to around 80,000 cycle tourism arrivals. Considering an average cost of 80 euros per person per day and an overnight stay of 3.7 nights (dividing the presences by the arrivals), an indirect income of around 23,680,000 euros is obtained.

By contrast, an estimate of the average expenditure of daily users, day hikers and residents is difficult to quantify, but a prediction has been made. The inhabitants present along the twenty-three Apulian municipalities crossed by the cycle path were considered, which amount to $€ 329,796$. It has been assumed that $2.5 \%$ will attend the track on a daily basis, spending an average of $€ 2$ per day. Obviously, not all days of the year were considered but "cycling days" amount to around 180 days (from April to September). An amount of $€ 2,968,200$ was therefore obtained. Adding the indirect revenues referring to 
cycle tourists and daily users, we find an annual indirect benefit of approximately $€ 26,648,200$ euros.

After analysing the indirect benefits, it is necessary to analyse the social economic benefits which are divided into two categories:

- quantitative benefits;

- qualitative benefits.

The former are of great importance with regard to job creation. From studies conducted by the Politecnico di Milano on the VenTo cycle path, it appears that a cycle path with a strong tourist value can generate around 2.9 new jobs per kilometer (https://www.cicloviavento.it/progetto/tracciato/). The VenTo cycle route obviously cannot be compared to the Bari cycle route since it crosses large urban centres such as Venice, Ferrara, Cremona, Pavia, Milan and Turin. For this reason, in our case, 1.5 new jobs have been hypothesised for kilometre.

Taking into account the fact that the average income per person in the Apulia Region is $€ 26,201.00$ and applying a conversion factor of 0.54 , it generates an increase in income of $€ 3,395,649.60$ (https://www.invitalia.it/chi-siamo/area-media/notizie-e-comunicatistampa/fondi-europei-online-la-guida-all-analisi-costi-benefici-dei-progetti-diinvestimento).

The qualitative/social benefits concern important factors such as public health, the environment and the territory crossed. Cycling is fun, it costs nothing, it frees cities and the countryside from cars and pollution and is good for your health. Scientific studies show that using the bike benefits the cardio-vascular system, the respiratory system and the muscular skeletal system. Two 15-minute bike rides a day are enough for a healthy heart. The bicycle improves blood circulation, helping to prevent the onset of heart attacks and swelling in the lower limbs. It is proven that cycling every day helps prevent: heart attack, hypertension, varicose veins in the lower extremities, obesity, muscle weakness, asthma, chronic bronchitis, orthopedic problems, gland diseases and sleep disturbances. Additionally, cycling makes you happy. In fact, physical activity releases endorphins (feel-good hormones) that help defeat depression, fatigue and daily stress.

The benefits generated by the use of the bicycle also concern the environment since cycling more would result in a significant reduction in $\mathrm{CO}_{2}$ given the zero-emission nature of the bike. For each kilometre travelled by bicycle, the community would earn $€ 0.16 / \mathrm{km}$, taking into account that a cyclist rides $15 \mathrm{~km}$ a day and 80,000 of them stay overnight in Puglia for 3.7 days, this would entail a benefit of $€ 710,400$.

The same calculation can be performed for the 8,245 local inhabitants who will use the cycle route and travel an average of $3 \mathrm{~km}$ a day. The resulting benefit is equal to $€ 712,368$.

We can define these benefits as positive externalities which occur when the beneficiaries of positive impacts produced by another subject do not pay a price equal to the benefits received.

It would be enough to cycle $5 \mathrm{~km}$ a day, instead of using motorised vehicles, to reach $50 \%$ of the proposed targets for reducing emissions.

In this phase, the financial values, excluding VAT, were transformed into economic values through the application of conversion factors. The conversion factors are the relationship between shadow prices and market prices. If the conversion factor for an asset is greater than 1, the observed price is less than the shadow price; this means that the opportunity cost of that asset is higher than that reflected by the market. Conversely, if the conversion factor is less than 1 , the observed price is higher than the shadow price due to taxes or other market distortions that add to the marginal social value of an asset 
(https://www.invitalia.it/chi-siamo/area-media/notizie-e-comunicati-stampa/fondieuropei-online-la-guida-all-analisi-costi-benefici-dei-progetti-di-investimento). From the data in Table 1, we can see how the social costs are equal to $€ 27,383,937.32$.

Table 1 - Determination of social costs

\begin{tabular}{lccc}
\hline & & $\begin{array}{c}\text { Conversion } \\
\text { factors }\end{array}$ & Totals \\
\hline $\begin{array}{l}\text { Realisation } \\
\text { costs }\end{array}$ & $€ 23,656,991.00$ & 1.0254 & $€ 24,257,878.57$ \\
$\begin{array}{l}\text { Managing } \\
\text { costs }\end{array}$ & $€ 3,544,284.30$ & 0.882 & $€ 3,126,058.75$ \\
Totals & & & $€ 27,383,937.32$ \\
\hline
\end{tabular}

The various benefits and costs associated with the construction of the cycle path have been listed. From this estimate, it appears that the SROI ratio is equal to 1.15, which means that the benefits are greater than the costs and the work can be performed (Table 2).

In the conducted analysis, maintenance costs for the construction of the cycle path were not considered. Taking into account that maintenance costs of $€ 1,050.00$ per $\mathrm{km}$ are expected on average. This would entail a total cost of $€ 168,000$. This cost would not significantly reduce the benefits deriving from its realisation.

\begin{tabular}{lr} 
Table 2 - Determination of SROI & \\
\hline Benefits & Values \\
\hline Income deriving from cycle tourists & $€ 23,656,991.00$ \\
Income from local inhabitants & $€ 2,968,200.00$ \\
Employment increase & $€ 3,395,649.60$ \\
$\mathrm{CO}_{2}$ reduction for cyclists & $€ 710,400.00$ \\
$\mathrm{CO} 2$ reduction for local inhabitants & $€ 712,368.00$ \\
Total benefits & $€ 31,466,617.60$ \\
& \\
Costs & Values \\
Realisation costs & $€ 24,257,878.57$ \\
Managing costs & $€ 3,126,058.75$ \\
Total costs & $€ 27,383,937.32$ \\
SROI & 1.15 \\
\hline
\end{tabular}

\subsubsection{Summary of the economic evaluation and SROI - Bari}

Figure 7 shows the Bari Biciplan where the different colours refer to the different areas where the segment of the route are realised. It is possible to perform a first assessment of the possible benefits deriving from the realisation of $30 \mathrm{kms}$ of bike paths planned and other traffic calming interventions for a total of 25 million euros. A full discussion of an Apulian cycle route is presented in Albergo, N. (2019), although it does not strictly refer to the case of Bari.

As previously mentioned, the first positive effect in terms of benefit derives from the use of the bicycle by the local population; for 180 days, this benefit amounts to $€ 2,968,200.00$ and accounts for $2 \%$ of the population. Furthermore, considering the environmental benefits in terms of $\mathrm{CO}_{2}$ reduction, for $3 \mathrm{~km}$ travelled per day, the benefit amounts to $€ 712,368.00$. 
Therefore, considering the total social costs of $€ 27,383,973.32$ and the social benefits of $€ 31,466,617.60$, the SROI calculation amounts to 1.15 . With this result, the positive repercussions in social and environmental terms are guaranteed. These results derive not only from the displacements of the local population explained here, but also from the presence of tourists. The urban ability to bike can, in our opinion, be considered as correlated to individual well-being, whilst at the same time being able to produce indirect benefits in relation to other abilities (for example, health, physical integrity, belonging, play and control of your environment) and therefore the general quality of life. Thus, SROI can be appreciated as an advanced method for evaluating social impacts and values and it indicates the validity of the project under evaluation.

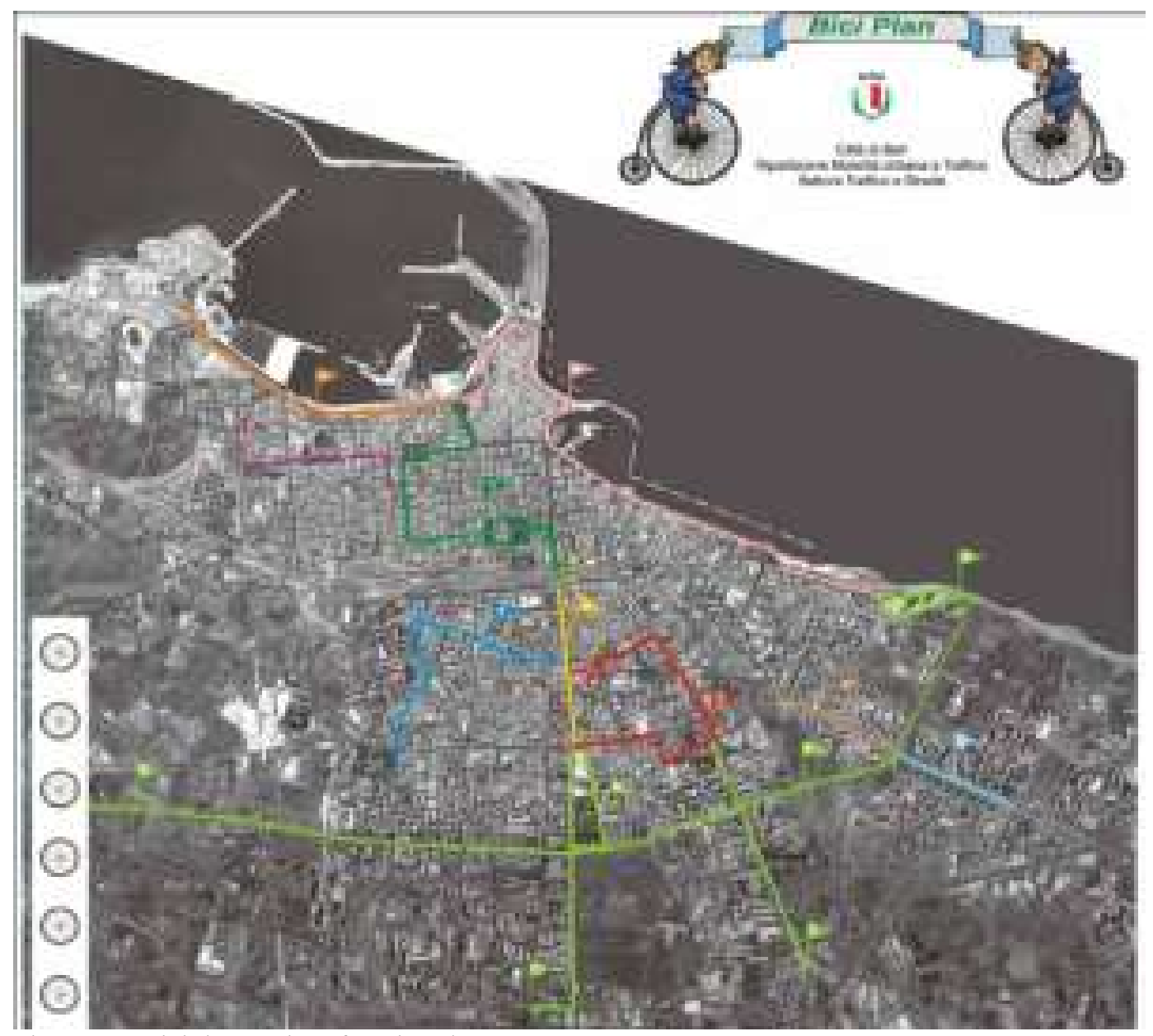

Figure 7 - Biciplan - City of Bari, Italy

Source: Città Metropolitana di Bari (2015)

\subsubsection{Economic evaluation and SROI - Krakow}

If we consider the calculation made for the Bari area with the Krakow case, and add up the values of the two corresponding investments of $€ 4,864,705.00$ and $€ 2,933,243.97$, respectively, it is possible to determine the total social benefits for the first project as $€ 109,933.33$ and social benefits as $€ 26,384.00$; for the second project, total benefits amount to $€ 136,317.33$, while total costs assigned to the projects in social terms are $€ 123,631.73$. These can be considered as incremental benefits from the starting solution. Therefore, the SROI, in incremental terms, is equal to $€ 12,685.60$, and as a ratio, this equates to 1.103 . 
In line with Campisi (2019), we can say that these results give prominence to the concept of cycling and of "walkability" as proxies of the accessibility quality or how much an urban environment is able to encourage cycling/walking, and to offer itself as a platform for a daily life based on pedestrian and cycling mobility. From these results, it transpires that improving traffic conditions with these two interventions means intervening on those extrinsic characteristics of people as a requirement of urban space that contributes to improving the quality of human life. From an environmental point of view, cycling and walking are "green" modes of transport, as they have a low environmental impact and cause no air and noise pollution. The presence of cycling and walkable environments and transit systems may create alternatives to private car usage, thus reducing traffic congestion, noise and emissions. Additionally, many recent health studies have demonstrated that cycling and walking can promote mental and physical health, including cardiovascular fitness and reduced stress, constituting physical activity of moderate intensity.

\subsection{Comparisons of the results}

The case studies show with absolute clarity the economic advantages attributable to society and to the environment deriving from the planned interventions, as presented in Table 3. The case of Bari presents social benefits of $€ 31,466,617.60$, while in case of Krakow, the two interventions of $900 \mathrm{~m}$ length in total, generates benefits of $€ 136,317.33$. In the case of Krakow, only cost data relating to the component of actual use by tourists and leisure activities were extrapolated, thus excluding the costs of restoring the road artery. In fact, while in the latter case the SROI falls below unity (0.017), in the case of the direct attribution of social costs and benefits to the projects, the SROI is equal to 1.103. The characteristic costs (Table 3 ) are those costs which are strictly related to the investment.

Both projects are feasible and generate benefits in socio-economic terms as the SROI is greater than 1. These outcomes can be interpreted as important results in methodological and analytical terms because they pave the way for the social and environmental appreciation of public investments, something that is not always explicit and appreciated in terms of evaluation. Therefore, the possibility of being able to proceed in this direction and to extend this methodology to all other cases of interventions of the same nature was demonstrated.

Table 3 - Comparison of the results between the city of Bari and the city of Krakow

\begin{tabular}{lcrr}
\hline \multicolumn{3}{c}{ Bari } & \multicolumn{1}{c}{ Krakow } \\
\hline Benefits & $€ 31,466,617.60$ & $€ 136,317.33$ & $€ 136,317.33$ \\
Social costs & $€ 27,383,937.32$ & $€ 7,797,948.97$ & $\begin{array}{c}€ 123,631.73 \\
\text { (full costs) }\end{array}$ \\
(characteristic costs) \\
SROI & 1.15 & 0.017 & 1.103 \\
\hline
\end{tabular}

\section{Conclusions}

This paper provides a reading of the existing literature on methodologies that are utilised for developing feasibility studies of investment projects applied to urban centres and to the transport sector. This innovative contribution is linked to the possibility of using SROI in the evaluation process to improve estimations and ex ante analyses.

Economic evaluation results which we obtained for the two case studies of Bari and Krakow suggest priorities for sustainable and social transport investments, by assuring 
the most important aims to be addressed in an urban context. In fact, in the two case studies presented as concrete examples of application, environmental and social aspects that are not common when evaluating the transport sector were assessed. The innovative evaluation approach therefore enforces the decision-making process and helps to properly allocate the economic resources (Venezia, 2019). It also overcome the evident limitations of a common cost-benefit analysis (Chi, Bunker, 2020). The methodological procedure adopted to perform the economic analysis, by also considering SROI, complies with the criteria established by the valuation techniques of public utility investments (according to the manual prepared by the Public Investment Evaluation Unit of the Ministry of the Budget and Economic Planning, https://www.mit.gov.it/sites/default/files/media/notizia/201707/Linee\%20Guida\%20Val\%20OO\%20PP_01\%2006\%202017.pdf ).

All the analyses were performed with consideration to the community's point of view, in fact, the individual cost and benefit items from transfers have been not considered because, in case in which the investor is represented by a public administration, it does not influence the feasibility assessment of the work.

The obtained results therefore show that the projects are highly justified. These projects should be prioritised, fast-tracked and developed in a concurrent manner to realise the intended results. The methodology adopted can be replicated elsewhere and also in some other research areas. In fact, these methodological applications have the possibility of being applied in all areas where social and environmental aspects are relevant. It follows that in the operational context of public administrations, it is possible to proceed with the use of the SROI for evaluation purposes. However, this methodological approach does not find its justification where the elements of sociality and environmental purposes are neither a priority, nor assume any relevance. These circumstances are more common in the private sphere and at the microeconomic level.

\section{Acknowledgments}

This paper is the result of the research collaboration of both authors under a visiting professorship grant (Decreto Prot. n. 0000328 dated 20/03/2019 - [UOR: SI000743 Classif. V/6]) at the University of Bari Aldo Moro. A three-month long visit of Prof. Lidia Zakowska from Cracow University of Technology, Poland, at the University of Bari Aldo Moro, Department of Economic and Finance took place from April to July 2019. Prof. Lidia Zakowska was working closely with Prof. Elisabetta Venezia, an expert on transportation economy, who was responsible for the scientific coordination of this research.

\section{References}

Albergo, N. (2019), "La realizzazione di una ciclovia: il caso dell'Acquedotto Pugliese", PG Thesis, University of Bari Aldo Moro, Bari, Italy.

Appel, T., Bezak, B., Isle, J. (2017), "DC Water Green Infrastructure Financing: Pay for Success Can Help Water Utilities Pursue Innovative Solutions", Journal of the American Water Works Association, Vol. 109, pp. 26-31.

Campisi, T, Canale, A., Tesoriere, G. (2019), "The development of walkability in the Historic centre of Enna: the case of Saint Tommaso neighbourhood", European Transport, Issue 73, paper no. 4. 
Chèze, C., Nègrec, R. (2017), "Wider economic impacts of high-speed rail: example of agglomeration benefits assessment on Bretagne Pays de Loire high speed rail project", Transportation Research Procedia, no. 25, pp. 5307-5324.

Chi, S., Bunker, J. (2020), An Australian perspective on real-life cost-benefit analysis and assessment frameworks for transport infrastructure investments, Research in Transportation Economics, 100946.

Child, C., Gibbs, B. G., Rowley, K. J. (2016), "Paying for success: An appraisal of social impact bonds", Global Economics and Management Review, Vol. 21, pp. 36-45.

Città Metropolitana di Bari (2015), Biciplan.

Cordes, J.J. (2017), "Using cost-benefit analysis and social return on investment to evaluate the impact of social enterprise: Promises, implementation, and limitations", Evaluation and Program Planning, Vol. 64, pp. 98-104.

Fraser, A., Tan, S., Lagarde, M., Mays, N. (2018), "Narratives of Promise, Narratives of Caution: A Review of the Literature on Social Impact Bonds", Social Policy \& Administration, Vol. 52, pp. 4-28.

Lane, M. J., (2015), The Mission-Driven Venture, John Wiley \& Sons, Inc., Hoboken, New Jersey.

Lombardo, G., Mazzocchetti, A., Rapallo, I. Tayser, N., Cincotti, S. (2019), Assessment of the Economic and Social Impact Using SROI: An Application to Sport Companies, Sustainability, Report.

Meira, L. Herszon, de Mello, C.A., Castro, M. Y., Oliveira, L.K., Nascimento, C.O.L. (2020), Measuring social effective speed to improve sustainable mobility policies in developing countries, Environment, Volume 78, 102200.

Melo, C., Teotónio, I., Matos, C., Carlos, S., Cruz O. (2020), "What's the economic value of greening transport infrastructures? The case of the underground passages in Lisbon", Sustainable Cities and Society, Vol. 56.

Ministerstwo Infrastruktury (2005), Polityka Transportowa Państwa na lata 2006-2025, Warszawa.

Ministerstwo Rozwoju Regionalnego (2012), Strategia rozwoju kraju (2020), Warszawa.

Urząd Miasta Krakowa, (2014), Studium uwarunkowań i kierunków zagospodarowania przestrzennego, Krakow.Ustawa o planowaniu i zagospodarowaniu przestrzennym z dnia 27 marca 2003 r., Dz.U. 2003 Nr 80 poz. 71.

Muvawala, J., Sebukeera, H., Ssebulime, K. (2020), Socio-economic impacts of transport infrastructure investment in Uganda: Insight from frontloading expenditure on Uganda's urban roads and highways, Research in Transportation Economics, 100971.

Nicholls, J. (2017), "Social return on investment - Development and convergence", Evaluation and Programme Planning, Vol. 64, pp. 127-135.

Pearce, D., 1998, "Cost benefit analysis and environmental policy", Oxford Review of Economic Policy, vol. 14, pp. 84-100.

Venezia, E. (2019), "The investment decision process: how to formulate proprieties in the transport sector", in Venezia, E. (ed.), The decision-making process for infrastructural investment choices, Franco Angeli, Milano.

Venezia, E., Pizzutilo, F. (2018), "SROI: a cost-inclusive evaluation method", International Conference on Traffic and Transport Engineering, Electronic Proceedings, ISBN 978-86-916153-4-5.

Venezia, E.-Pizzutilo, F. (2020), "Evaluation Tools for Transport Infrastructures: Social Return On Investments", European Transport, Issue 76, paper no. 7. 
Warner, M.E. (2013), "Private finance for public goods: social impact bonds", Journal of Economic Policy Reform, Vol. 16.

Wright, S., Nelson, J.D., Cooper, J.M., Murphy, S. (2009), "An evaluation on the transport employment (T2E) scheme in Highland Scotland using social return on investment (SROI)", Journal of Transport Geography, Vol. 17, pp. 457-467.

Yates, B.T., Marra, M. (2017a), "Introduction: Social Return On Investment (SROI)", Evaluation and Program Planning, Vol. 64, pp. 95-97.

Yates, B.T., Marra, M. (2017b), "Introduction: Social Return On Investment (SROI), Problems, solutions....and is SROI a good investment?", Evaluation and Program Planning, Vol. 64, pp. 136-144.

Zakowska, L., Starowicz, W., Pulawska, S., (2012), "Geographic/Demographic Accessibility of Transport Infrastructure (GDATI)", in Hull, A., Silva, C., \& Bertolini, L. (Eds.), Accessibility Instruments for Planning Practice, Porto, COST Office.

Zakowska, L., et al., (2019), "GDATI for Public Transport Accessibility Evaluation and Service. Development in Selected Regions of Krakow City Area", in Silva, C., Bertolini, L., Pinto, N. (Eds), Designing accessibility instruments. Routledge, Taylor \& Francis,

Wielka lokacja Krakowa 1257. In http://www.lokacjakrakow.tron.pl

Krajowa Polityka Miejska, Ministerstwo Infrastruktury i Rozwoju, 2014.

Zintegrowany Plan Rozwoju Transportu Publicznego dla Krakowa, Uchwala Nr LX/774/08 Rady Miasta Krakowa, 2008.

https://ecf.com/sites/ecf.com/files/Charter_of_Brussels.pdf

https://por.regione.puglia.it/en/homepage

https://www.cga.ct.gov/2007/rpt/2007-R-0635.htm

www.regione.puglia.it

https://www.gazzettaufficiale.it/eli/id/2014/4/7/14G00069/sg

https://www.federalismi.it/nv14/articolo-documento.cfm?Artid=32540

https://www.parlamento.it/parlam/leggi/003401.htm

http://krakow.pl/aktualnosci/231765,29,komunikat,krakowianie_coraz_chetniej_wsiadaj

a na rowery.html

https://www.cicloviavento.it/progetto/tracciato/

https://www.agenziapugliapromozione.it/portal/

https://www.invitalia.it/chi-siamo/area-media/notizie-e-comunicati-stampa/fondi-

europei-online-la-guida-all-analisi-costi-benefici-dei-progetti-di-investimento

https://www.mit.gov.it/sites/default/files/media/notizia/2017-

07/Linee\%20Guida\%20Val\%20OO\%20PP 01\%2006\%202017.pdf

\section{Author contributions}

The authors confirm contribution to the paper as follows: study conception and design - E. Venezia, L. Zakowska; data collection - E. Venezia for the Italian case study and L. Zakowska for the Polish case study. Both authors analysed and gave an interpretation of the results; both authors prepared the draft manuscript. Both authors reviewed the results and approved the final version of the manuscript. 